\title{
Relating firing rate and spike time irregularity in motor cortical
}

\section{neurons}

\author{
Adrián Ponce-Alvarez*, Bjørg Elisabeth Kilavik and Alexa Riehle
}

\author{
Address: Institut de Neurosciences Cognitives de la Méditerranée, CNRS-Université de la Méditerranée, Marseille, France \\ Email: Adrián Ponce-Alvarez* - adrian.ponce@incm.cnrs-mrs.fr \\ * Corresponding author
}

from Eighteenth Annual Computational Neuroscience Meeting: CNS*2009

Berlin, Germany. 18-23 July 2009

Published: 13 July 2009

BMC Neuroscience 2009, 10(Suppl I):P298 doi:I0.I I86/I47|-2202-I0-SI-P298

This abstract is available from: http://www.biomedcentral.com/I47I-2202//0/SI/P298

(c) 2009 Ponce-Alvarez et al; licensee BioMed Central Ltd.

\section{Introduction}

Cortical neurons exhibit highly irregular inter-spike intervals (ISIs) [1]. Differences in irregularity could be in part due to imbalances of excitatory and inhibitory inputs to the neurons, which determines the statistics of the net input [2]. There is experimental evidence that the intrinsic irregularity of neurons in the awake monkey is constant [3]. However, changes in irregularity have also been reported $[4,5]$ in different cortical areas and different behavioral tasks. The classical measure of spike time irregularity is the coefficient of variation (CV), a global measure defined as the dispersion of the ISIs. However, the CV largely overestimates the irregularity in the case of pronounced changes in firing rate. This led several researchers to propose alternative measures of irregularity that are local in time and therefore relatively independent of rate changes. To our knowledge, these measures have never been compared to each other. Here we compare four such measures: the local coefficient of variation CV2 [6], the local variation LV [3], the measure IR [4] and the measure SI [7]. The first question we address is which of these measures is the most efficient for analyzing experimental data in a time-resolved manner where the number of ISIs is limited. Second, we study the variation of the spike time irregularity of neurons recorded in the motor cortex of a monkey while performing a delayed center-out task.

\section{Results}

By calculating analytically the statistics of the measures in the case of gamma-distributed spike trains we found that the CV2 is the measure with the lowest variance and, thus, it induces the least errors when the number of ISIs in each window is limited. The application of CV2 to recorded spike trains in the motor cortex of a monkey performing a delayed motor task provides an overview of the diversity of behaviors of the spike time irregularity, that can be modulated or not by the task, and decoupled or not from rate modulations. In our dataset the $\mathrm{CV} 2$ and firing rate are either negatively correlated (55.1\% of the neurons) or decoupled ( $44 \%$ of the neurons). Positive correlations are seldom $(0.9 \%)$. Neurons with a CV2-rate decoupling have a rather constant CV2 and discharge mainly irregularly, reflecting a balance drive. Neurons with a CV2-rate coupling can modulate their $\mathrm{CV} 2$ and explore a larger range of CV2 values, reflecting an excitatory drive.

\section{References}

I. Softky WR, Koch C: The highly irregular firing of cortical cells is inconsistent with temporal integration of random EPSPs. J Neurosci 1996, I 3:334-350.

2. Salinas E, Sejnowski TJ: Impact of correlated synaptic input on output firing rate and variability in simple neuronal models. J Neurosci 2000, 20:6193-6209.

3. Shinomoto $S$, Shima K, Tanji K: Differences in spiking patterns among cortical neurons. Neural Computation 2003, I 5:2823-2842.

4. Davies RM, Gerstein GL, Baker N: Measurement of timedependent changes in the irregularity of neural spiking. J Neurophysiol 2006, 96:906-918.

5. Compte A, Constantinidis C, Tegnér J, Raghavachari S, Chafee MV, Goldman-Rakic PS, Wang XJ: Temporally irregular mnemonic persistent activity in prefrontal neurons of monkeys during a delayed response task. J Neurophysiol 2003, 90:344I-3454.

6. Holt GR, Softky WR, Koch C, Douglas RJ: Comparison of discharge variability in vitro and in vivo in cat visual cortex neurons. J Neurophysiol 1996, 75: I806-1814. 
7. Miura K, Okada M, Amari M: Estimating spiking irregularities under changing environments. Neural 2006, 18:2359-2386.

Publish with Bio Med Central and every scientist can read your work free of charge

"BioMed Central will be the most significant development for disseminating the results of biomedical research in our lifetime." Sir Paul Nurse, Cancer Research UK

Your research papers will be:

- available free of charge to the entire biomedical community

- peer reviewed and published immediately upon acceptance

- cited in PubMed and archived on PubMed Central

- yours - you keep the copyright 